\title{
Clients' perception of antenatal care services in a tertiary hospital in North Eastern Nigeria
}

\author{
Sanusi M. Ibrahim ${ }^{1 *}$, Maisaratu Bakari ${ }^{2}$, Hadiza U. Abdullahi ${ }^{1}$, Mohammed Bukar ${ }^{1}$
}

\begin{abstract}
${ }^{1}$ Department of Obstetrics and Gynecology, University of Maiduguri Teaching Hospital, Maiduguri, Borno State, Nigeria

${ }^{2}$ Department of Obstetrics and Gynecology, Federal Medical Centre Yola, Adamawa State, Nigeria
\end{abstract}

Received: 30 July 2017

Accepted: 01 September 2017

\section{*Correspondence:}

Dr. Sanusi M. Ibrahim,

E-mail: ozovehesan@yahoo.co.uk

Copyright: () the author(s), publisher and licensee Medip Academy. This is an open-access article distributed under the terms of the Creative Commons Attribution Non-Commercial License, which permits unrestricted non-commercial use, distribution, and reproduction in any medium, provided the original work is properly cited.

\section{ABSTRACT}

Background: The study determined and documented the level of satisfaction and quality of care of patients attending the antenatal clinic of University of Maiduguri Teaching Hospital. It was a cross sectional study.

Methods: Using an interviewer administered questionnaire whose contents were synthesized from validated Patient Satisfaction Questionnaire III (PSQ III), information on clients' satisfaction was obtained from 274 women attending antenatal care clinic. Data were entered in to the IBM SPSS software, and analysed. Some variables were reduced to binomial scale with two categories in order to ease the process of logistic regression. P value $<0.05$ at $95 \%$ confidence interval was considered significant.

Results: The study showed an excellent level of satisfaction of clients with services obtained from our facility. Majority of respondents, $99(36.1 \%)$ were aged of 20-24 years, with most of them having education above primary school level- 99 (36.1\%). Although most of the clients, $158(57.7 \%)$ were unskilled, majority of the clients' husbands, $136(49.6 \%)$ were middle level workers. However, logistic regression of all the significant determinants of patients' overall satisfaction of quality of ANC services- clients' occupation, educational status, enjoying full medical services, having enough time with doctors and access to hospital, good registration process and effective ANC laboratory, showed that none of the factors was a predictor of clients' satisfaction.

Conclusions: Periodic patient satisfaction survey should be institutionalized to provide feedback for continuous quality improvement.

Keywords: Clients’ perception, Patient satisfaction, Quality of care, Tertiary hospital

\section{INTRODUCTION}

The quality of health care delivery is best assessed by a measure of the extent to which a patient is content with the care received from the health care provider.

Patient satisfaction is a major component of quality of health care and is critical to how well patients do. Patient satisfaction and quality of care exist together as hospitals whose patients reported being highly satisfied had higher quality care. ${ }^{1,2}$
Hospitals are no more just a symbol of humanitarian services. Clients are increasingly concerned about hospital's performance with focus on resources, quality and effectiveness of services delivered by these hospitals. ${ }^{3}$ Improving the quality of care and service delivery in current practice focus more on quality assurance process with the patient as the focus point.

Research from The Gambia and Sudan has shown that user experience is influenced to a great extent by factors such as the type of facility either public or private, with 
those attending public facilities less satisfied than those attending private facilities. ${ }^{4,5}$ Other factors influencing patient satisfaction in this region include communication with, and attitudes of care providers, waiting time, inadequate privacy and lack of space in the public facilities.

In a study from Ethiopia, satisfaction with the health care services was found to have significant association with the age and educational level of the patient. Other factors such as lack of drugs and suppliers, poor cleanliness, amenities and water supply have been shown to negatively influence patient satisfaction in some part of developing world. .,7 $^{6}$

Antenatal care is a focused strategy for reducing maternal mortality. According to the 2013 Nigeria demographic and health survey ${ }^{8}$ the maternal mortality ratio was $576 / 100,000$ live births with only 36 per cent of deliveries occurring in health facilities. Cost and distance from the health facility have been cited as a great impediment. However, 7\% of mothers from some part of Nigeria reported lack of trust for the provider or poor quality service as their reason for not delivering in health facility. ${ }^{8}$ Antenatal care service utilization in some part of Nigeria is low due to poor quality services which borders on finance, transportation, hospital bureaucracy and patient waiting time..$^{9,10}$ To reduce maternal mortality and increase access to care in this country, patient satisfaction is a valuable tool.

The study was aimed at determining and documenting the level of satisfaction and quality of care of patients attending the antenatal clinic of University of Maiduguri Teaching Hospital (UMTH) so that there will be a benchmark of service delivery upon which improvement can be made.

\section{METHODS}

This was a cross sectional study conducted at the antenatal clinic of the UMTH, Maiduguri, Borno State North-east Nigeria from $1^{\text {st }}$ January to $26^{\text {th }}$ February 2015. UMTH is a tertiary health institution and is the only functional teaching hospital in the north-eastern region of Nigeria. It is located in the central part of Maiduguri, the capital city of Borno state which lies between latitude $10^{\circ}$ and $14^{\circ}$ north and longitude $14^{0}$ and $45^{0}$ east. The 2006 Nigerian census puts the population of Borno state at $4,151,193$ with $1,990,036$ females. ${ }^{11}$

The hospital has an established Obstetrics and Gynaecology department which provides comprehensive gynaecological, family planning, antenatal, intrapartum and postnatal obstetric care. The antenatal clinic is run 3 times a week- Tuesdays for antenatal booking clinic visit and Wednesdays and Thursdays for antenatal follow up clinic visits. The booking clinic has annual population of 3,574 clients. The annual turnover of antenatal follow up clinics is 16,607 . The clinic usually commences with interactive health talks that cover various reproductive health issues including danger signs of pregnancy, prevention of diseases such as HIV/AIDS, cervical cancers, STIs and malaria.

Education on diet and nutrition, immunization and breast feeding is also done. The entire activities last for about an hour. Vital signs are taken and urinalysis is done to check for presence of protein and glucose. Laboratory service is offered in the clinic and this enables on the spot sample collection for routine investigations without clients needing to go to the hospital laboratory.

The study population was clients on follow up antenatal clinic visits. Women attending antenatal booking and post-natal clinics were excluded. The instrument for the study was a pre-tested interviewer administered questionnaire whose contents were synthesized from validated Patient Satisfaction Questionnaire III (PSQ III) designed by Ware JE, et al. in $1978 .{ }^{12}$ The questionnaire was divided into sections: Socio-demographic and obstetric characteristics, Services/procedures, Content of health information and education, Cost implication, Attitude of health personnel, Waiting time, Effective communication and Overall rating of antenatal care services. The questionnaires were administered in English language but translation to native language was done when necessary during the course of data collection.

Satisfaction of clients was measured by Likert scale. ${ }^{13}$ The scores were marked using a 5-point scale in descending order as fully satisfied ( 5 points), satisfied (4 points), uncertain (3 points), dissatisfied (2points) and very dissatisfied (1 point). Antenatal Care (ANC) was defined as health care given to a woman during pregnancy. Waiting time was defined as time spent from the end of the health talk to the beginning of the clinic consultation.

The sample size was derived using Kish's formula ${ }^{14}$

$\mathrm{n}_{\mathrm{f}}=\frac{n}{1+\frac{(n)}{N}}$

where $\mathrm{nf}$ is the desired sample size when population is less than $10,000, \mathrm{n}$ is the desired sample size when population is greater than 10,000 and $\mathrm{N}$ is the estimate of the population size $(3,574$ representing the annual antenatal booking clinic attendees at the study centre). $n$ was calculated to be 236 using Taylor's formula,

$\mathrm{n}=\frac{z^{2} p q}{d^{2}}$

where $\mathrm{z}$ is the standard normal deviate (1.96) at $95 \%$ confidence interval, $p$ is the proportion of the target population estimated to be satisfied with ANC services $(81.1 \%)$ which was extrapolated from finding of a similar study conducted in Ibadan, South-West Nigeria $q$ is the proportion of failure which is $1.0-\mathrm{p}$ and $\mathrm{d}$ is the degree of 
accuracy set as $0.05 .^{7}$ Consequently, the sample size, nf, with $20 \%$ attrition was 274 .

A total of 274 clients were recruited consecutively from the population of antenatal care clinic women after ethical approval from the research and ethical committee of University of Maiduguri Teaching Hospital, and after obtaining informed consent from them.

\section{Statistical analysis}

The data was entered in to the IBM SPSS software version 20.0 (New York, 2011). Frequency and percentage analyses were done for the sociodemographic characteristics, and chi square analysis was performed to identify variables that had significant influence on client satisfaction. The data was also reduced to binomial scale with two categories of satisfied and not satisfied in order to ease the process of statistical analysis, particularly logistic regression which was utilized to identify predictors. $\mathrm{p}$ value $<0.05$ at $95 \%$ confidence interval was considered significant.

\section{RESULTS}

All the 274 clients interviewed gave complete responses to all the items in the questionnaire. Overall 269 (98.2\%) of clients were satisfied with services rendered in our centres. The age ranged from 15-44 years with mean age of 26.1 years \pm 5.8 years.

Table 1 shows the sociodemographic characteristics of respondents. Majority of respondents, 99 (36.1\%) were aged of 20-24 years, followed by age group 25-29 years which accounted for $76(27.7 \%)$. Minority of the clients, $4(1.5 \%)$ were Aged 40-44 years. One hundred and twenty two $(44.5 \%)$ respondents were kanuris. Hausas were the next major clients constituting 32 (11.7\%) of all the women interviewed, followed by Fulani ethnic group which accounted for $29(10.6 \%)$ of the clients. Igbos and Yorubas accounted for $9(3.3 \%)$ and $7(2.6 \%)$ of the clients respectively. Fifty five clients $(20.1 \%)$ were from minority ethnic groups numbering 9 .

Two hundred and fifty (91.2\%) were of Islamic faith while $24(8.8 \%)$ were Christians. Most of the clients, 158 $(57.7 \%)$ were unskilled while $78(28.5 \%)$ and $38(13.9 \%)$ were middle-level workers and professionals respectively. However, most of the clients' husbands, 136 $(49.6 \%)$ were middle level workers while 81 (29.6\%) and $57(20.8 \%)$ were professionals and unskilled workers respectively. Analysis of the educational status revealed that most of the clients had education above primary school level- $99(36.1 \%)$ and $95(34.7 \%)$ had tertiary and secondary school levels of education respectively. Only $25(9.1 \%)$ of them had primary school level of education while $55(20.1 \%)$ had no formal education. Ninety nine $(36.1 \%)$ and $95(34.7 \%)$ of the clients were para 2-4 and para 1 respectively while minority, $37(13.5 \%)$ were para 0 .
Table 1: Sociodemographic characteristics of respondents.

\begin{tabular}{|c|c|c|}
\hline Characteristics & Frequency & $\%$ \\
\hline \multicolumn{3}{|l|}{ Age (Yrs) } \\
\hline $15-19$ & 21 & 7.7 \\
\hline $20-24$ & 99 & 36.1 \\
\hline $25-29$ & 76 & 27.7 \\
\hline $30-34$ & 51 & 18.6 \\
\hline $35-39$ & 23 & 8.4 \\
\hline $40-44$ & 4 & 1.5 \\
\hline Total & 274 & 100 \\
\hline \multicolumn{3}{|l|}{ Tribe } \\
\hline Hausa & 32 & 11.7 \\
\hline Kanuri & 122 & 44.5 \\
\hline Fulani & 29 & 10.6 \\
\hline Shuwa & 20 & 7.3 \\
\hline Igbo & 9 & 3.3 \\
\hline Yoruba & 7 & 2.6 \\
\hline Others & 55 & 20.1 \\
\hline Total & 274 & 100 \\
\hline \multicolumn{3}{|l|}{ Religion } \\
\hline Islam & 250 & 91.2 \\
\hline Christianity & 24 & 8.8 \\
\hline Total & 274 & 100 \\
\hline \multicolumn{3}{|l|}{ Occupation } \\
\hline Professionals & 38 & 13.9 \\
\hline Middle level & 78 & 28.5 \\
\hline Unskilled & 158 & 57.7 \\
\hline Total & 274 & 100 \\
\hline \multicolumn{3}{|l|}{ Occupation } \\
\hline Professionals & 81 & 29.6 \\
\hline Middle level & 136 & 49.6 \\
\hline Unskilled & 57 & 20.8 \\
\hline Total & 274 & 100 \\
\hline \multicolumn{3}{|l|}{ Educational status } \\
\hline No formal Education & 55 & 20.1 \\
\hline Primary & 25 & 9.1 \\
\hline Secondary & 95 & 34.7 \\
\hline Tertiary & 99 & 36.1 \\
\hline Total & 274 & 100 \\
\hline \multicolumn{3}{|l|}{ Parity } \\
\hline 0 & 37 & 13.5 \\
\hline 1 & 95 & 34.7 \\
\hline $2-4$ & 99 & 36.1 \\
\hline 5 or more & 43 & 15.7 \\
\hline Total & 274 & 100 \\
\hline
\end{tabular}

Table 2 shows the assessment of the health topics and amenities provided at the antenatal clinic. Overall, majority of the clients agreed to receiving adequate health topics $(72.8 \%$ versus $16.1 \% ; \chi 2=0.748, \mathrm{P}<0.0001)$. For individual variables, $236(86 \%)$ agrees that education on diet and nutrition was adequate while $22(8 \%)$ believed it was not adequate. Similarly, 239 (87\%) clients agreed that education on danger signs of pregnancy was adequate while $25(9 \%)$ said it was not adequate. This trend is same for education on breast feeding, family 
planning, prevention of malaria, STIs, HIV/AIDs and cervical cancer, as well as breast self-examination where majority of the clients where more than $50 \%$ of the clients agreed that it was adequate.

Table 2: Assessment of health topics.

\begin{tabular}{|llllll|}
\hline Health Topics & Strongly Agree & Agree & Uncertain & $\begin{array}{l}\text { Disagree } \\
\text { Strongly } \\
\text { disagree N }(\%)\end{array}$ \\
\hline Diet and nutrition & $\mathbf{N}(\%)$ & $\mathbf{N}(\%)$ & $\mathbf{N}(\%)$ & $\mathbf{N}(\%)$ & $2(1)$ \\
\hline Danger signs of pregnancy & $116(42)$ & $120(44)$ & $16(6)$ & $20(7)$ & $3(1)$ \\
\hline Breast feeding & $109(40)$ & $130(47)$ & $10(4)$ & $22(8)$ & $5(2)$ \\
\hline Family planning & $90(33)$ & $121(44)$ & $34(12)$ & $24(9)$ & $10(4)$ \\
\hline Prevention of malaria & $89(32)$ & $116(42)$ & $30(11)$ & $29(11)$ & $6(2)$ \\
\hline STIS & $90(33)$ & $119(43)$ & $24(9)$ & $35(13)$ & $6(2)$ \\
\hline HIV/AIDS & $81(29)$ & $103(38)$ & $43(16)$ & $41(15)$ & $7(3)$ \\
\hline Cervical cancer & $98(36)$ & $115(41)$ & $25(9)$ & $29(11)$ & $23(8)$ \\
\hline Breast self-examination & $69(25)$ & $74(27)$ & $40(15)$ & $68(25)$ & $27(10)$ \\
\hline
\end{tabular}

Table 3: Assessment of influence of sociodemographic factors on service satisfaction.

\begin{tabular}{|c|c|c|c|c|c|}
\hline \multirow{2}{*}{ Factor } & \multicolumn{2}{|c|}{ Overall Satisfaction } & \multirow{2}{*}{ Total } & \multirow{2}{*}{$x^{2}$} & \multirow{2}{*}{ p value } \\
\hline & Satisfied & Not Satisfied & & & \\
\hline \multicolumn{6}{|l|}{ Age (Yrs) } \\
\hline $15-19$ & $18(94.7)$ & $1(5.3)$ & 19 & \multirow{6}{*}{0.982} & \multirow{6}{*}{0.964} \\
\hline $20-24$ & $89(97.8)$ & $2(2.2)$ & 91 & & \\
\hline $25-29$ & $69(97.2)$ & $2(2.8)$ & 71 & & \\
\hline $30-34$ & $50(98.0)$ & $1(2.0)$ & 51 & & \\
\hline $35-39$ & $23(95.8)$ & $1(4.2)$ & 24 & & \\
\hline $40-44$ & $4(100)$ & $0(0.0)$ & 4 & & \\
\hline \multicolumn{6}{|l|}{ Tribe } \\
\hline Kanuri & $110(98.2)$ & $2(1.8)$ & 112 & \multirow{7}{*}{7.320} & \multirow{7}{*}{0.292} \\
\hline Hausa & $25(100)$ & $0(0.0)$ & 25 & & \\
\hline Fulani & $32(100)$ & $0(0.0)$ & 32 & & \\
\hline Shuwa & $17(94.4)$ & $1(5.6)$ & 18 & & \\
\hline Igbo & $7(87.5)$ & $1(12.5)$ & 8 & & \\
\hline Yoruba & $8(100)$ & $0(0.0)$ & 8 & & \\
\hline Others & $50(94.3)$ & $3(5.7)$ & 53 & & \\
\hline \multicolumn{6}{|l|}{ Religion } \\
\hline Islam & $229(97.9)$ & $5(2.1)$ & 234 & \multirow{2}{*}{3.657} & \multirow{2}{*}{0.114} \\
\hline Christianity & $20(90.9)$ & $2(9.1)$ & 22 & & \\
\hline \multicolumn{6}{|l|}{ Occupation } \\
\hline Professionals & $29(87.9)$ & $4(12.1)$ & 33 & \multirow{3}{*}{13.164} & \multirow{3}{*}{0.001} \\
\hline Middle level & $72(97.3)$ & $2(2.7)$ & 74 & & \\
\hline Unskilled & $146(99.3)$ & $1(0.7)$ & 147 & & \\
\hline \multicolumn{6}{|l|}{ Educational status } \\
\hline No formal Education & 47 (97.9) & $1(2.1)$ & 48 & \multirow{4}{*}{7.484} & \multirow{4}{*}{0.024} \\
\hline Primary & $20(100)$ & $0(0.0)$ & 20 & & \\
\hline Secondary & $90(100)$ & $0(0.0)$ & 90 & & \\
\hline Tertiary & $91(93.8)$ & $6(6.2)$ & 97 & & \\
\hline \multicolumn{6}{|l|}{ Husbands' occupation } \\
\hline Professionals & 75 (94.9) & $4(5.1)$ & 79 & \multirow{3}{*}{2.322} & \multirow{3}{*}{0.313} \\
\hline Middle level & $123(98.4)$ & $2(1.6)$ & 125 & & \\
\hline Unskilled & $50(98)$ & $1(2.0)$ & 51 & & \\
\hline \multicolumn{6}{|l|}{ Parity } \\
\hline 0 & $29(93.5)$ & $2(6.5)$ & 31 & \multirow{4}{*}{2.865} & \multirow{4}{*}{0.413} \\
\hline 1 & $82(96.5)$ & $3(3.5)$ & 85 & & \\
\hline $2-4$ & $90(97.8)$ & $2(2.2)$ & 92 & & \\
\hline 5 or more & $38(100)$ & $0(0.0)$ & 38 & & \\
\hline
\end{tabular}


Table 3 shows the influence of clients' sociodemographic characteristics on the overall level of satisfaction of the quality of ANC services in our health facility. Only clients' occupation $(\chi 2=13.164, \quad \mathrm{P}=0.001)$, and educational status $(\chi 2=7.484, \mathrm{P}=0.024)$ were significant determinants of overall satisfaction of the quality of antenatal care services. Age, tribe, religion, husbands' occupation and parity were not found to be significant determinants.

Table 4: Assessment of influence of technical quality, communication and financial aspects on service satisfaction.

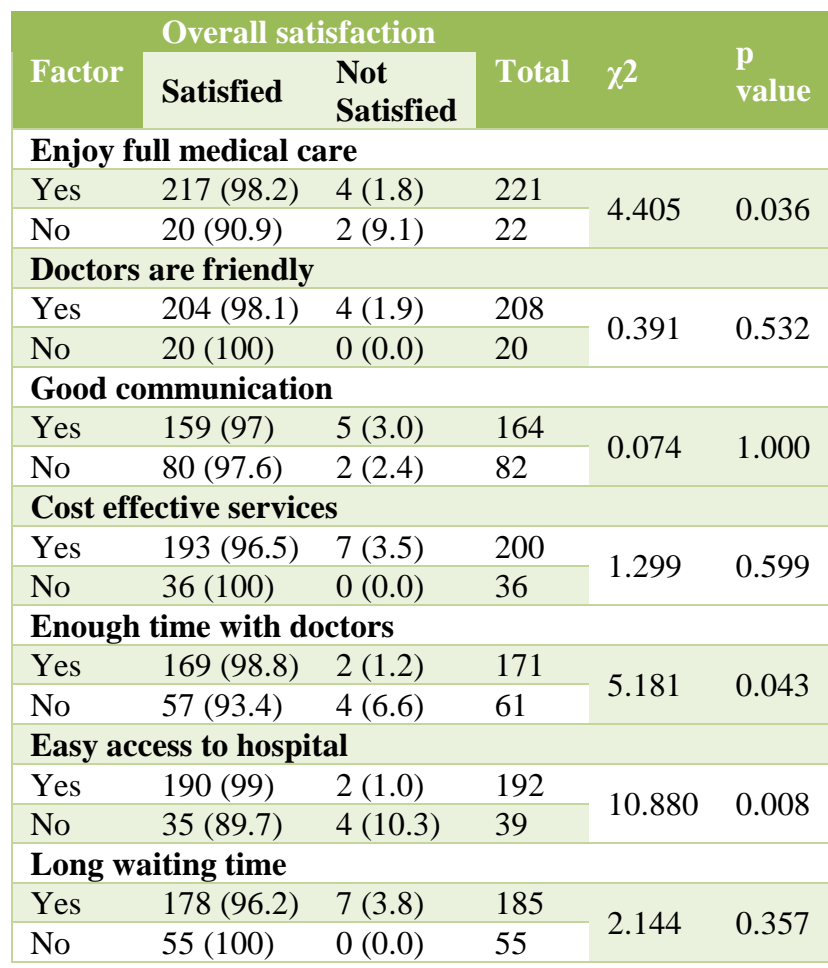

Table 4 shows the assessment of influence of some aspects of technical quality, communication and finances on the overall satisfaction of quality of ANC services.

From the table, clients who enjoyed full medical care $(\chi 2=4.405, \mathrm{P}=0.036)$, had enough time with doctors $(\chi 2=5.181, \mathrm{P}=0.043)$, and had easy access to hospital $(\chi 2=10.880, \mathrm{P}=0.008)$ were more likely to have overall satisfaction with the quality of ANC. Doctors being friendly, good communication, cost effective services and waiting time at the clinic did not influence the satisfaction of the clients.

Good registration process $(\chi 2=6.396, \mathrm{P}=0.028)$, and effective ANC laboratory $(\chi 2=6.910, \mathrm{P}=0.045)$ were the two logistics in the ANC that positively influenced clients' overall satisfaction, as shown in table 5. Other logistic activities such as assessment of vital signs, good reception at labour ward, good water and electricity supply, and good toilet hygiene did not significantly influence satisfaction.
Table 5: Assessment of influence of activities and hygiene on service satisfaction.

\begin{tabular}{|c|c|c|c|c|c|}
\hline \multirow[b]{2}{*}{ Factor } & \multicolumn{2}{|c|}{ Overall satisfaction } & \multirow[b]{2}{*}{ Total } & \multirow[b]{2}{*}{$x^{2}$} & \multirow[b]{2}{*}{$\begin{array}{l}\mathbf{p} \\
\text { value }\end{array}$} \\
\hline & Satisfied & $\begin{array}{l}\text { Not } \\
\text { Satisfied }\end{array}$ & & & \\
\hline \multicolumn{6}{|c|}{ Good registration process } \\
\hline Yes & $174(98.9)$ & $2(1.1)$ & 176 & \multirow{2}{*}{6.396} & \multirow{2}{*}{0.028} \\
\hline No & $50(92.6)$ & $4(7.4)$ & 54 & & \\
\hline \multicolumn{6}{|c|}{ Vital signs are taken } \\
\hline Yes & $225(97.8)$ & $5(2.2)$ & 230 & \multirow{2}{*}{1.556} & \multirow{2}{*}{0.284} \\
\hline No & $12(92.3)$ & $1(7.7)$ & 13 & & \\
\hline \multicolumn{6}{|c|}{ Effective ANC laboratory services } \\
\hline Yes & $217(98.2)$ & $4(1.8)$ & 221 & \multirow{2}{*}{6.910} & \multirow{2}{*}{0.045} \\
\hline No & $14(87.5)$ & $2(12.5)$ & 16 & & \\
\hline \multicolumn{6}{|c|}{ Good reception at labour ward } \\
\hline Yes & $155(98.1)$ & $3(1.9)$ & 158 & \multirow{2}{*}{2.086} & \multirow{2}{*}{0.189} \\
\hline No & $29(93.5)$ & $2(6.5)$ & 31 & & \\
\hline \multicolumn{6}{|c|}{ Good water supply } \\
\hline Yes & $226(97.4)$ & $6(2.6)$ & 232 & \multirow{2}{*}{0.053} & \multirow{2}{*}{1.000} \\
\hline No & $2(100)$ & $0(0.0)$ & 2 & & \\
\hline \multicolumn{6}{|c|}{ Good electricity supply } \\
\hline Yes & $222(96.9)$ & $7(3.1)$ & 229 & \multirow{2}{*}{0.315} & \multirow{2}{*}{1.000} \\
\hline No & $10(100)$ & $0(0.0)$ & 10 & & \\
\hline \multicolumn{6}{|c|}{ Good toilet hygiene } \\
\hline Yes & $183(97.3)$ & $5(2.7)$ & 188 & \multirow{2}{*}{0.015} & \multirow{2}{*}{0.690} \\
\hline No & $42(97.7)$ & $1(2.3)$ & 43 & & \\
\hline \multicolumn{6}{|c|}{ Recommend hospital to family and friends } \\
\hline Yes & $243(97.6)$ & $6(2.4)$ & 249 & \multirow{2}{*}{0.025} & \multirow{2}{*}{0.976} \\
\hline No & $1(100)$ & $0(0.0)$ & & & \\
\hline
\end{tabular}

Logistic regression of all the significant determinants of patients' overall satisfaction of quality of ANC servicesclients' occupation, educational status, enjoying full medical services, having enough time with doctors and access to hospital, good registration process and effective ANC laboratory, showed that none of the factors was a predictor of clients' satisfaction.

\section{DISCUSSION}

Antenatal care is a very important component of maternal healthcare services. It gives women and their families an opportunity to learn about the risk associated with pregnancy and guides their health seeking practices and decision- making, thereby preventing maternal and infant morbidity and mortality.

Our study evaluated the perception of patients and their level of satisfaction with antenatal care. Like our study, previous researches have revealed positive correlation between patient's satisfaction and health care utilization..$^{15,16}$ The predominant age group of respondents of 20-24 years found in our study is similar to a study carried out in Lagos which recorded 20-29 years. ${ }^{17}$ This age group reflects the age of increased reproductive capacity.

The overall satisfaction of clients with services received from our centre was $98.2 \%$ which was higher than those 
reported from Ibadan (75\%), Enugu (53\%) and Kano $(83 \%) .{ }^{18-20}$ Apart from variation in the way services are delivered, differences in study populations and hence patients' expectation could affect satisfaction level.

A high proportion of the patients were also satisfied with the ease of accessing care from our centre (99\%). This is in contrast with findings from other studies, where lower proportions of patients were satisfied with ease of accessing care as reported by $84 \%$ in Kano $56 \%$ in Benin city $49 \%$ in Ile-Ife and $53 \%$ in Enugu. ${ }^{19-22}$ Apart from location of our facility within the capital city, less bureaucracy might have contributed to patient satisfaction.

The high level of satisfaction with payment $(96.5 \%)$ obtained in this study may have resulted from the safety net provided by the social welfare department, the public sector National Health Insurance Policy (NHIS), the retainership clinic and the comparative low charges in the hospital compared to private health facilities.

Patient waiting time in outpatient clinics is often the major reason for patients' complaints regarding their experiences in outpatient clinics. Therefore, patient satisfaction with waiting time plays a crucial role in the overall satisfaction with services. In this study, waiting time had the highest proportion of satisfied patients $(96.2 \%)$. This is in keeping with a study carried out in Nnewi Nigeria where waiting time was perceived by respondents as being adequate. ${ }^{23}$

This study found that excellent proportions of patients were satisfied with the quality of medical care and services provided by the doctors. Good communication between patients and care providers has been described as an important component of good medical practice and in present study, 97\% of those who enjoyed good communication reported satisfaction with services rendered. ${ }^{1,4}$

Some of the factors that attract patients to the health facility are the availability of facilities for good registration process, effective laboratory services, good reception at labour ward, good water and electricity supply and good toilet hygiene. In the present study $97.6 \%$ of the respondents were satisfied and willing to recommend the hospital to family and friends.

A number of limitations did exist in the study. Firstly, the excellent overall satisfaction by respondents should be interpreted with caution as literature has shown that pregnant women tend to be relatively uncritical, and accept as appropriate whatever care they receive. ${ }^{24}$ Secondly, the quantitative nature of the study was a potential limitation, as patients may have certain important beliefs that could not be expressed using a quantitative survey tool. In addition, the most recent visit might not represent the patient's cumulative experience across all visits. Finally, the results cannot really be generalized to other Northeast region of Nigeria.

Overall, the study showed a high level of satisfaction of patients with services obtained from our facility. Periodic patient satisfaction survey should be institutionalized to provide feedback for continuous quality improvement.

\section{ACKNOWLEDGMENTS}

Authors would like to thank all the doctors and nurses who joined us in conducting antenatal clinic for the clients during the period of study.

\section{Funding: No funding sources}

Conflict of interest: None declared

Ethical approval: The study was approved by the Institutional Ethics Committee

\section{REFERENCES}

1. Tsai TC, Orav EJ, Jha AK. Patient satisfaction and quality of surgical care in US Hospital. Annal Surg. 2015;261(1):2-8.

2. Pindar RJ, Ferguson J, Moller H. Minority ethnicity patient satisfaction and experience: results of the national cancer patient experience Survey in England. BMJ Open. 2016;6(6):e011938.

3. Jorge MA, Herga P, Ahmed A. Client satisfaction and quality of health care in rural Bangladesh. Bull WHO. 2001;79:512-7.

4. Jallow IK, Chou YJ, Liu TL, Huang N. Women's perception of antenatal care services in public and private clinics in the Gambia. Int J Quality Health Care. 2012;24(6):595-600.

5. Zeidan ZA, Idris AM, Bhairy NM. Satisfaction among pregnant women towards antenatal care in public and private care clinics in Khartoum. Khartoum Med J. 2011;4(2):590-5.

6. Assefa F, Mosse A. Assessment of Clients' satisfaction with health service deliveries at jimma university specialized hospital. Ethiopian J Health Sci. 2011;21(2):101-10.

7. Nwaeze IL, Enabor OO, Oluwasola TAO, Aimakhu CO. Perception and satisfaction with quality of antenatal care services among pregnant women at the University College Hospital, Ibadan, Nigeria. Ann Ibd Pg Med. 2013;11(1):22-28.

8. National Population Commission (NPC) [Nigeria] and ICF International. Nigeria Demographic and Health survey 2013. Abuja, Nigeria, and Rockville, Maryland, USA: NPC and ICF International. 2014:127-154.

9. Fagbamigbe AF, Idemudia ES. Barriers to antenatal care use in Nigeria: evidences from non-users and implications for maternal health programming. BMC Pregnancy Childbirth. 2015;15:95.

10. Iloh G, Ofoedu JN, Njoku PU, Odu FU, Ifedigbo $\mathrm{CV}$, Iwuamanam KD. Evaluation of patients' satisfaction with quality of care provided at the 
National Health Insurance Scheme clinic of a tertiary hospital in South-Eastern Nigeria. Niger J Clin Pract. 2012;15:469-74.

11. Federal Government of Nigeria. Report on 2006 Census final results. Federal Government printer Abuja. 2009;96:B39.

12. Ware JE Jr, Davies-Avery A, Stewart AL. The measurement and meaning of patient satisfaction. Health Med Care Serv Rev. 1978;1(1):1,3-15

13. How to use Lickert scale. Available at http://www.ehow.com/how_4855078_use-likertscale-statisticalanalysis.html\#ixzz1KycvDyp2. [accessed on 18/04/2013]

14. Kish L. Survey Sampling. J Royal Statistical Soc. 1969;132(2):272-4.

15. Oladapo OT, Iyaniwura CA, Sule-Odu AO. Quality of Antenatal services at primary health care level in southwest Nigeria. Afr J Reprod Health. 2008;12(3):71-92.

16. Deccacche A. Evaluating quality and effectiveness in the promotion of health: approaches and methods of public health and social sciences. Promot Educ. 1997;4(2):10-5.

17. Sholeye OO, Abosede OA, Jeminusi OA. Client perception of antenatal care services at primary health care centers in an urban area of Lagos, Nigeria. World J Med Sci. 2013;8(4):359-364.

18. Olusina AK, Ohaeri JU, Olatawura MO. Patient and staff satisfaction with quality of in-patient psychiatric care services in a Nigerian general hospital. Soc Psychiatr Epidemiol. 2004;37(6):283-8.

19. Eze CU. Survey of patient satisfaction with obstetrics ultrasound at the university of Nigeria teaching hospital Enugu, Nigeria. Niger J Health Biomed. 2006;5(1):93-97.

20. Iliyasu Z, Abubakar IS, Abubakar S, Lawan UM, Gajida AU. Patients' satisfaction with services obtained from Aminu Kano Teaching Hospital, Kano. Northern Nigeria. Nigeria J Clin Pract. 2010;13(4):371-8.

21. Ofili AN, Ofovwe CE. Patients' assessment of efficiency services at teaching hospital in a developing country. Ann Afr Med. 2005;4(4):150-3.

22. Afolabi MO, Erhun WO. Patients' response to waiting time in an outpatient pharmacy in Nigeria. Trop J Pharm Res. 2003;2(2):207-214.

23. Nnebue CC, Ebenebe UE, Adinma ED, Iyoke CA, Obionu CN, Ilika AL. Clients' Knowledge, perception and satisfaction with quality of maternal health care services at the primary health care level in Nnewi, Nigeria. Nigerian J Clin Pract. 2014;17(5):594-601.

24. Porter M, Macintyre S. What is, must be best: a research note on conservative or deferential responses to antenatal care provision. Soc Sci Med 1984;19:1197-200.

Cite this article as: Ibrahim SM, Bakari M, Abdullahi HU, Bukar M. Clients' perception of antenatal care services in a tertiary hospital in North Eastern Nigeria. Int J Reprod Contracept Obstet Gynecol 2017;6:4217-23. 